\title{
Inhibitor Effect of N-(5-((4-chlorophenyl)diazenyl)-2-hydroxy benzylidene)-2-hydroxy benzohydrazide for Mild Steel Corrosion in chloride and sulphate acidic solutions
}

\author{
G. Pandimuthu ${ }^{1,2}$, K.Muthupandi ${ }^{3}$, Tse-Wei Chen ${ }^{4,5}$, Shen-Ming Chen ${ }^{4, *}$, A.Sankar $^{1, *}$, \\ P. Muthukrishnan ${ }^{6}$, Syang-Peng Rwei ${ }^{5,7}$ \\ ${ }^{1}$ Department of Chemistry, Kandaswami Kandar's College, P.Velur, Namakkal-638 182, India. \\ ${ }^{2}$ Department of Chemistry, Arumugam Pillai Seethai Ammal College, Tiruppatur-630211, India. \\ ${ }^{3}$ Department of Chemistry, Mannar Thirumalai Naicker College, Madurai-625004, India. \\ ${ }^{4}$ Electroanalysis and Bioelectrochemistry Lab, Department of Chemical Engineering and \\ Biotechnology, National Taipei University of Technology, No. 1, Section 3, Chung-Hsiao East Road, \\ Taipei 106, Taiwan, ROC. \\ ${ }^{5}$ Research and Development Center for Smart Textile Technology, National Taipei University of \\ Technology, Taipei 106, Taiwan, ROC \\ ${ }^{6}$ Department of Chemistry, Faculty of Engineering, Karpagam Academy of Higher Education, \\ Coimbatore-641021, India. \\ ${ }^{7}$ Institute of Organic and Polymeric Materials, National Taipei University of Technology, Taiwan \\ *E-mail: smchen78@ms15.hinet.net, sanvishnu2010@gmail.com
}

Received: 2 August 2021 / Accepted: 17 September 2021 / Published: 10 October 2021

Corrosion resistance of N-(5-((4-chlorophenyl)diazenyl)-2-hydroxybenzylidene)-2-hydroxybenzo hydrazide (CDHBHZ) in reducing mild steel (MS) corrosion in $1 \mathrm{M}$ hydrochloric acid $(\mathrm{HCl})$ and $0.5 \mathrm{M}$ sulphuric acid $\left(\mathrm{H}_{2} \mathrm{SO}_{4}\right)$ were examined by Electrochemical and Chemical techniques. The results from mass loss analysis revealed that the corrosion rate of MS enhanced when the temperature was raised from $308 \mathrm{~K}$ to $328 \mathrm{~K}$. It is noted that in the acidic solutions, the dissolution rate of MS reduced with raise in the concentration of CDHBHZ (0.01- $0.03 \mathrm{M})$ and it resulted in higher inhibition rate in $\mathrm{HCl}$ than $\mathrm{H}_{2} \mathrm{SO}_{4}$ solution. The diameter of the semicircle increased as the amount of CDHBHZ increased, as shown by the Nyquist plots. The protection efficacy of CDHBHZ was $96.00 \%$ (1M HCl) and $89.00 \%$ $\left(0.5 \mathrm{H}_{2} \mathrm{SO}_{4}\right)$ at the ideal CDHBHZ concentrations. CDHBHZ functions as a comprehensive inhibitor that predominantly inhibit corrosion at anodic site, according to Polarization studies. The IR spectroscopic analysis confirms the functional groups in the CDHBHZ and the formation of inactive thin films on MS surface. The adsorption of CDHBHZ on the MS follows Langmuir model, according to Thermodynamic and adsorption studies.

Keywords: Alloys, Hydrazone, Corrosion reduction rate, Chemical analysis, Langmuir model. 
(C) 2021 The Authors. Published by ESG (www.electrochemsci.org). This article is an open access article distributed under the terms and conditions of the Creative Commons Attribution license (http://creativecommons.org/licenses/by/4.0/). 